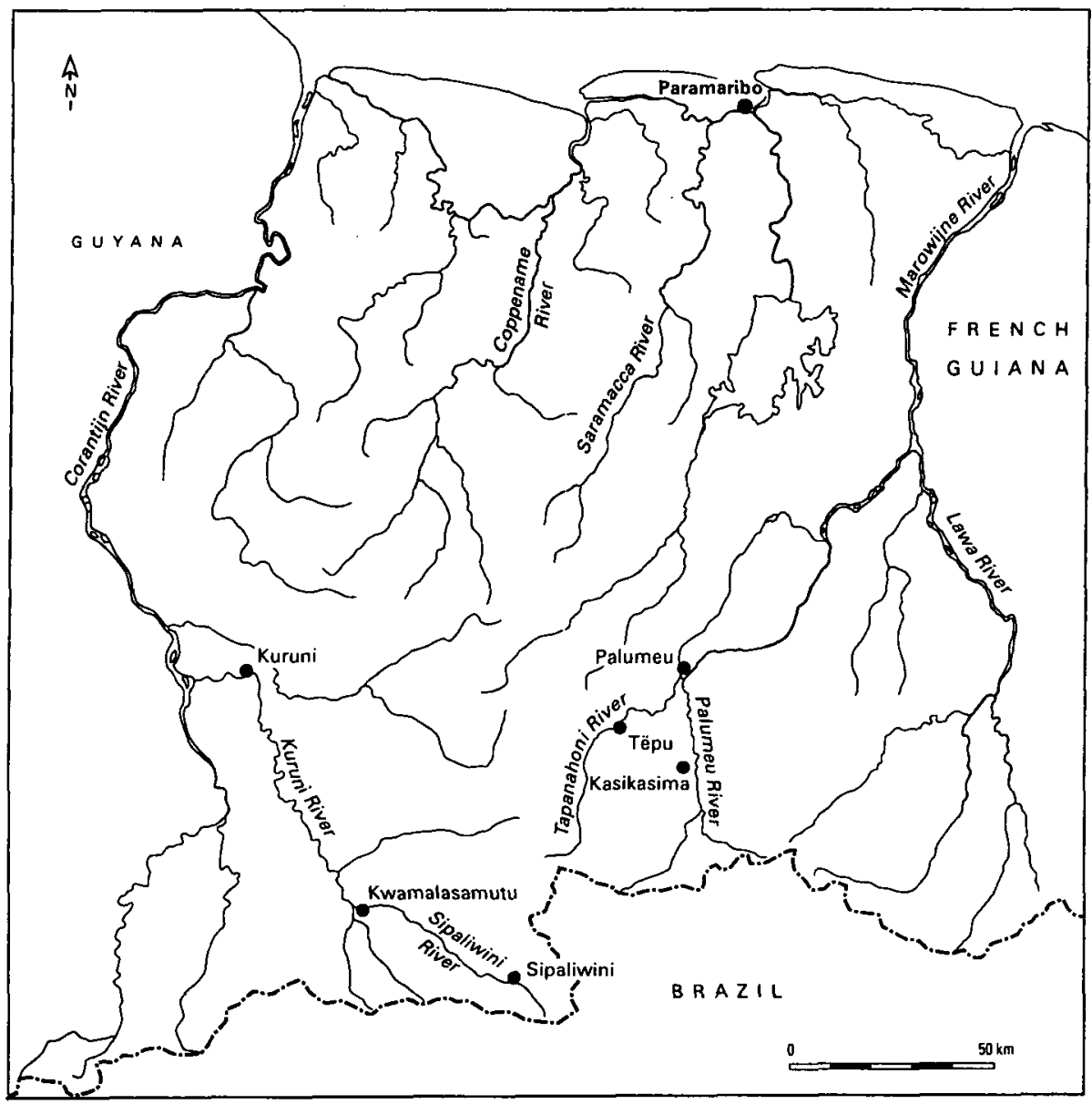

Current Trio settlements in Suriname 
Eithne B. Carlin

\title{
SPEECH COMMUNITY FORMATION: A SOCIOLINGUISTIC PROFILE OF THE TRIO OF SURINAME
}

\author{
Mar ná beidh ár leithéidí arís ann \\ Because the likes of us will never be again \\ Tomás Ó Criomhthain, An t-Oileánach
}

\section{INTR ODUCTION}

Fear with a pinch of jealousy and contempt, based on a mutual lack of understanding or knowledge, could succinctly characterize the relationship obtaining between the coastal Creoles and the Amerindians of the interior of Suriname. ${ }^{\prime}$ After the tenth warning, from various inhabitants of Paramaribo, to be careful I began to wonder what I had let myself in for. I was setting out to spend three months living with the Trio, to study their language and to document it before whatever malevolent forces might render either one of us in the past tense. Trio is namely one of the many vanishing Cariban languages in the Guianas. The urgency with which I started later seemed slightly misplaced as I learned to understand not just their language but also their resilience.

The ethnographic descriptions of the Trio that exist, range in scope from the records of early travelers and anthropologists to the extensive monograph of Peter Rivière (1969). Linguistic information, apart from some early wordlists, is utterly lacking, that is, we know next to nothing about the Trio language nor indeed about the group as a minority speech community. The present paper aims to fill this gap. In the following I bring together both extralinguistic factors such as historical, economic, sociological, and cultural factors that have and still contribute to and are crucial 
in determining the present-day status of the Trio and their language and internal sociolinguistic factors, that is, factors that influence the choice of what the Trio speak to whom, how, and when. It will be shown that Trio is sociolinguistically-speaking in a strong position and that, paradoxically enough, it has undergone an expansion with other smaller groups assimilating to it. Another surprising feature of the Trio setting, and one that can be seen to contribute to the dominance of the Trio language, is that although the Trio live in a multilingual environment, multilingualism is virtually absent. Nor have any of the other Amerindian languages spoken in the Trio villages had any impact on Trio. So one wonders, have any of the contacting languages had any influence on the language at all? The article finishes by looking at the extent and result of contact within the wider context of Suriname and the role of Sranantongo and Dutch.

\section{PRESENT-DAY ETHNODEMOGRAPHY AND ECONOMY}

According to the Trio themselves as well as missionary sources, the group numbers approximately 1,500 and is found in the deep south of Suriname on either side of the Brazil-Suriname border. In both countries they make up less than 1 percent of the total population, and thus constitute a nonunique minority with minority status in both countries. ${ }^{2}$ While I shall make reference to those living in Brazil where relevant, this paper is designed to describe the sociolinguistic situation of the Trio of Suriname.

Fifteen-hundred constitutes a small group considering that the total population of Suriname numbers about 430,000 inhabitants, two thirds of whom reside in Paramaribo and its environs. Just over 2 percent of this number accounts for the indigenous population which numbers almost 10,000 Amerindians who belong to two major linguistic families, the Cariban and the Arawakan. The Fifth General Population and Housing Census of 1980, which was published in 1996, gives the number of Arawaks as 1,787 and the number of Caribs as 2,200. The Caribs proper, i.e. the Kariña, and the Arawaks live in the coastal region of Suriname. The socio-cultural and linguistic situation of the coastal groups differs radically from that of the groups in the interior in that an on-going process of assimilation into the larger Suriname society is resulting in the decline and demise of both their cultures and their languages. By contrast, the relative isolation of the location of the Trio enables them to live as a more or less autonomous group, a state within a state, for the most part uninvolved in central government. ${ }^{3}$

The Trio are in general self-sufficient. The Trio diet consists of meat and 
fish which is consumed in great quantities and supplemented by root crops. The division of labor is along gender lines with mainly the women being responsible for the crops. The staple food is cassava, other foods being bananas, pineapples, sugar-cane, sweet potatoes, eddoes, yams, and maize. Calabashes, gourds, cotton, and tobacco are also grown. In the largest village, Kwamalasamutu, there is now also small-scale rice- and peanut-planting, with the latter also being practiced in Palumeu now. Fields are cut and cleared by men, both sexes take part in the planting, and thereafter the fields are taken care of by the women. Hunting and fishing are mainly carried out by men who never travel alone but only enter the forest with either their hunting dog, or sometimes just a man with his wife or sister, or they travel in small groups of two or three men. When the men return from a hunting expedition with a good catch, the next few days are spent eating it until it is finished. Small-scale fishing is practiced by women.

Thus the immediate environment, that is, the forest and their plots of land, provide the Trio with food and housing. ${ }^{4}$ What is not readily available is modern equipment such as saws to cut down trees; outboard motors for their boats, and radios. Nowadays the Trio need this equipment, as well as clothes and other non-native items, and to be able to trade for or buy these some contact with the rest of the country is necessary. In what follows we look at the immediate Trio environment and their contact possibilities both within their own settlements and outside of these.

\section{SETTLEMENT PATterns and POPUlation CONSTITUTION}

The Trio inhabit four main settlements in the southern part of the tropical rain forest of Suriname, the home of at most 1,500 speakers, and three settlements in the western Tumuc-Humac region of the Pará region of Brazil with a population of approximately 700 speakers. There is steady contact between the Trio living in Suriname and those in Brazil.5 The population concentrations in the Trio villages, as given on the map below, are the following: approximately 50 Trio live in Sipaliwini on the Sipaliwini River; approximately 50 people live in Palumeu on the Tapanahoni River; between 200 and 300 live in Tëpu on the Upper Tapanahoni River. By far the largest concentration is found in the village Kwamalasamutu on the Sipaliwini River with between 800-1000 inhabitants. The village Alalaparu, which is often mentioned in the modern ethnographic literature, no longer exists but has been reclaimed by the forest. Its former inhabitants now live in Kwamalasamutu and in Tëpu. 
The present settlement pattern is no longer the traditional one since formerly the Trio lived in villages of between fifteen and fifty inhabitants. Frikel's statistics average out at approximately thirty inhabitants per village (Frikel 1957:514), and in 1941, twenty-five Trio villages were counted in Suriname (Schmidt 1942). This is in sharp contrast with the situation today of four larger settlements and two outliers. The larger focused settlements were set up by missionaries in the early 1960s. In the areas of health and education there are obvious advantages in greater population concentrations insofar as it is easier to administer and monitor health care and set up and man educational facilities. All the villages in which the Trio live are isolated, that is, they are in the forest region of Suriname, there are no roads to the villages, they can only be reached by boat and walking or by plane. Each of the villages has an airstrip. Sometimes there are up to four planes arriving a week but sometimes, depending on the weather or necessity of flights, there may not be a single flight for two or three weeks. Besides the four main villages mentioned above, there are also a few families from Kwamalasamutu now living in Amatopo and Coeroenie (Kuruni) close to the border with Guyana, these number about ten people in each location. The Trio there work at the airstrips. ${ }^{6}$

Despite the relative isolation in which the Trio live, communication between the villages is excellent. Apart from radio contact every evening and morning between all the villages, the Trio travel a lot between the villages, so that there is always someone bringing news.

In addition, the Trio often live longer periods of their lives in different villages so that most families and relationships are known to most people. By way of contrast, most non-Amerindians who come to the villages do not stay for longer periods so that there is little continuity from the outside. Distances between the villages vary from half a day to up to a week, most journeys requiring both walking and canoeing. Such long-distance boat trips are now made with outboard motors but the frequency of trips is also partly determined by the availability of gasoline which is flown in from the capital.

The present-day population of the Trio villages comprises at least ten groups of people of ethnic descent other than Trio and is the result of migration and convergence. ${ }^{7}$ Early historical accounts as given in Whitehead (1988) relate that the Carib groups of the Guianas in general lived in large settlements of between a few hundred and a few thousand inhabitants. Trio oral traditions likewise tell us that the ancestors of the Trio lived in one large settlement in Samuwaka in Brazil. It was from this settlement that they later scattered in all directions because of a depletion 
of game resources in the area (cf. Koelewijn 1984:252 and 1987:262). Ethnographers and travelers from the late eighteenth century onwards found the Trio in small autonomous scattered settlements over the southern part of Suriname, interspersed with or adjacent to other non-Trio groups. It is these groups that have now for the most part merged resulting in at least one large polyethnic settlement in Kwamalasamutu (cf. Table 2). Of these we know that the Waiwai and the Waiwai subgroups, as well as the Sikiyana came from the west. The Akuriyo were a small nomadic group and the Wayana were further to the north of the Trio and had been at war with the Trio. The convergence process has resulted in language shift which in turn, for some of the languages involved, has brought in its wake the death of the original languages and at the same time an expansion of Trio,

However, not all the non-ethnic Trio have fused with the Trio, that is, the status of Wayana is somewhat different from, for example, that of most of the other groups given below in that it exists elsewhere in Suriname as an independent language and the number of Wayana in the Trio villages is small and is the result of inmarriage. The case of the Akuriyo who have assimilated linguistically but who socially are not seen as being on a par with their Trio patrons is discussed in the section "Power and language" below. Starting from the village of Palumeu, I give in the following the population breakdown and concentrations in each of the villages. The population of Palumeu is more or less equally balanced between Trio and Wayana and together they number approximately one hundred. Palumeu is exceptional in that its population does not represent a homogeneous speech community, rather each of these groups speaks their own language without there being any stable bilingualism. The population of Tëpu consists mostly of Trio with a few inmarried Wayana and the greater part of the approximately fifty-strong Akuriyo group. Sipaliwini consists mostly of Trio. The population constitution for these three villages is summarized in Table 1, followed by the ethnodemographic information for Kwamalasamutu.

Table 1. Population Constitution and Numbers ${ }^{8}$

\begin{tabular}{lrcc} 
& Trio & Wayana & Akuriyo \\
\hline Palumeu & 50 & 50 & 1 \\
Tëpu & 200 & 10 & 30 \\
Sipaliwini & 80 & 3 & $?$ \\
\hline
\end{tabular}


The most dense polyethnic concentration, consisting of about ten originally different groups, is found in Kwamalasamutu. On the macro level, no distinction is made between the Trio and the non-original Trio, neither by the Trio themselves nor in this paper, and all the village inhabitants, with the possible exception of a very few old Akuriyo women, speak Trio as their primary language. The status of the Wayana differs from that of the other groups in that they do not form a unit within the villages, rather they constitute isolated instances of inmarried elements. The other Cariban groups, who over the last century have fused with the Trio, are now, at least as regards their linguistic behavior, acculturated Trio forming a relatively homogeneous speech community. However, on the micro level a distinction is made and is of relevance for our understanding of both the history and the culture of the Trio and the non-Trio groups. An overview of the population of Kwamalasamutu based on ethnic descent is given in Table 2.

Table 2. Population Constitution in Kwamalasamutu Based on Ethnic Descent

\begin{tabular}{llrrr}
\hline Group Name & Name Variations & $\begin{array}{c}\text { No. in } \\
\text { Suriname }\end{array}$ & $\begin{array}{c}\text { Other Location } \\
\text { if applicable }\end{array}$ & $\begin{array}{c}\text { Linguistic } \\
\text { Classification }\end{array}$ \\
\hline Trio & Tarëno, Tirìyó & 450 & Brazil & Cariban \\
Akuriyo & (Wama) Akoerio & 50 & (Brazil) & Cariban \\
Aramayana & Aramagoto & $?$ & - & Cariban \\
Okomoyana & Komayana & 150 & - & Cariban \\
Sakëta & - & 100 & - & Cariban \\
Sikiyana & Chikena, Tshikiana & 50 & - & Cariban \\
Waiwai & Wayway & 1 & Guyana, Brazil & Cariban \\
Sirewu & Shereó & 10 & Brazil? & Cariban \\
Tunayana 9 & Tonayena & 80 & - & Cariban \\
Mawayana & - & 60 & Brazil & Carib./Arawakan \\
\hline
\end{tabular}

The recurrent ending -yana in the above table indicates groups of humans or "people" and can be found all over the Guiana region. Other such morphemes are -koto and -sana and variations thereof. According to De Goeje (1924:214), names ending in -koto/-goto are only found in Cariban groups, whereas -jana/-yana/-ana and -enne are found in Cariban, Arawakan, and Tupi names. In Trio -jan, as well as -san, is a collective plural marker only used to mark human entities.

Names for ethnic groups in the southern part of Suriname are assigned according to three main strategies, that is, names are either descriptive or they are taken from the domains of nature (animals, birds, bees) or material culture (arrows). Most of the names we meet in the relevant literature are taken from the domain of nature. ${ }^{10}$ Some examples are given in Table 3. 
Table 3. Naming Strategies

\begin{tabular}{ll}
\hline Group & Meaning \\
\hline Arimihoto & Spider monkey \\
Maipurisana & Tapir \\
Pijanakoto & Eagle \\
Aramayana & Sweat bee \\
Pïrëujana & Arrow \\
Inkarijana & those behind (the mountain) \\
\hline
\end{tabular}

The autonym for the Trio is tarëno. According to Rivière (1969:11) tarëno is the autonym for the westerly group, and tirizo the autonym for the easterly group with the latter term also being used by the Wayana for the Trio. The name Tarëno, however, is not found in the literature until Rivière (1969), yet this is the name that is found in the Trios' own oral history. The rest of the population in Suriname, as far as they are aware of their existence as a group, as well as the academic world, refers to the group by the name Trio; in Brazil, the term Tiriyo is used. The Trio refer to their language as tarëno i-jomi "Trio his/their-language." Structurally both tarëno and tïriyo would seem to be descriptive terms but as yet I have been unable to discover their meaning. ${ }^{11}$

The term Tarëno can be used as a singular and as a plural (the Trio) and can be pluralized by the suffix -ton as in tarëno-ton, resulting in an individualizing plural form, which denotes all the Trio subgroups as well. According to my informants, in order to distinguish between the "original" or non-mixed Trio, that is, those not mixed by intermarriage with, for example the Aramayana, Okomoyana etc., the term piropï (pl. pirropi-ton) is used. Pirop $\ddot{i}$ is a body part term meaning "chest" and its usage as an ethnonym is to designate those living in the middle (of the forest). In this context piropi could be translated by Inner Trio, those of the central kernel of the Trio, the "pure, unmixed" Trio. Informants say that this term is also used by the Brazilian Trio to refer to the Trio of Suriname.12 The tribes to the west of the Trio, namely the Waiwai, refer to the Trio as yawi who in turn refer to the Waiwai by a descriptive term inkarijana from inka "back (anat.)" which means those living behind the mountain.

\section{LANGUAGE SHIFT TO TRIO}

With the exception of Mawayana, which may be a mixed language, all of the names given in Table 2 are of groups belonging to the larger Cariban language family. ${ }^{13}$ The internal classification of the Cariban family is not 
altogether clear, mainly due to the lack of detailed linguistic descriptions of the relevant languages. Furthermore, there is considerable disagreement as to how many languages even make up the Cariban family with numbers ranging between thirty-nine and sixty. Since the various internal classifications of this family are dealt with critically in Gildea (1992), only a summary is given in the following. A classification by Girard ${ }^{14}$ posits fifteen subgroups and assigns Trio to group 7, named the Tiriyó group, which contains ten other languages, among them Pianakoto which Frikel (1964) claims to be identical to Trio. ${ }^{15}$ Table 4 gives the different classifications of the Trio group. Durbin's (1977) classification of the Cariban languages is the one that is referred to most often in Cariban studies although it too clearly exhibits discrepancies that arise from the lack of sound language descriptions. Durbin posits two branches, namely Northern and Southern Cariban. He sets up a Trio group, comprising ten languages, in ,the subgroup East-West Guiana of the Northern Cariban branch. Kaufman posits a Trio group subdivided into three separate subgroups, Tiriyó, Karihona, and Salumá, with the entire group consisting of five languages. Table 4 shows the lack of consensus with regard to which languages are to be included in the group. It should be noted that these classifications are mainly based on older wordlists of some of the languages whereas there were no data at all available on others.

Table 4. The Trio Group Classifications

\begin{tabular}{lll}
$\begin{array}{l}\text { Girard's group 7 } \\
\text { Tiriyó }\end{array}$ & $\begin{array}{c}\text { Durbin's Northern Cariban } \\
\text { East-West Guiana }\end{array}$ & $\begin{array}{c}\text { Kaufman's D(-E-F) } \\
\text { Guiana Branch Tiriyó } \\
\text { group D1: Tiriyó subgroup }\end{array}$ \\
\hline $\begin{array}{l}\text { Tiriyó } \\
\text { Wama }\end{array}$ & $\begin{array}{l}\text { Trio-Rangu } \\
\text { Wama (Akurio) }\end{array}$ & $\begin{array}{l}\text { Tiriyó } \\
\text { Akuriyo } \\
\text { D2: Karihona subgroup } \\
\text { Hianákoto-Umawa }\end{array}$ \\
Carijona & & Kanákoto \\
& & Karihona \\
Saluma & Salumá \\
Urukuena & Saluma & \\
Tiriometesem & Urukuyana & \\
Pauxi & Triometesen & \\
Pianakoto & Pauxi & \\
Guake & Pianakoto & \\
& & \\
& Kumayena & \\
\hline
\end{tabular}


According to the numbers given in Tables 1 and 2, the populations of all the Trio villages are of mixed ethnic descent and approximately half the population in Kwamalasamutu does not belong to the core Trio group. However, the dominant language in all the villages except Palumeu is Trio. Indeed one of most surprising features of this polyethnic population makeup in these villages in the south of Suriname is the utter lack of multilingualism. One can assume that the older migrating groups were at least bilingual and that the break in transmission of their native languages began with their advent in the Trio villages and was practically completed within three generations. With the exception of Aramayana and Okomoyana who have no speakers left, it is now only speakers of fifty years and older who communicate with each other in their original languages. In the home, even where there are grandparents and parents speaking their original languages, the children, although they can understand these languages, only speak Trio.

The process of population shift leading to the present structure results from small groups or perhaps family units moving into a probably only slightly larger settlement and forming a minority group there and eventually becoming absorbed by the dominant group. It can be observed in the Guiana region that this process may result in layers of both population and language shift, as neighboring groups assimilate first to one larger neighbor and then to another; this would seem to have been the case with the Mawayana who were originally Arawakan, who shifted to Waiwai and then again to Trio. Some of the groups listed in Table 2 have completed the process of absorption and the original name only refers to their ancestry but no longer to any cultural or linguistic differences. These are in particular the Aramayana and the Okomoyana. As a result there is a higher degree of linguistic homogeneity than might be expected in such a conglomeration of ethnic diversity.

Language shift is associated with language loss, when an ethnic group gives up its own language and replaces it with another. While language loss is attested in the Trio villages, some languages do exist outside of the Trio settlements, thus not all population and language shift situations have the same devastating results of language death induced by shift, at least not within a few generations as has been the case in the Trio villages.

The Akuriyo began shifting to Trio in the 1970s when they were brought in by missionaries to live in Tëpu. There are reports of between four and ten Akuriyo living in Brazil, none of whom speak Akuriyo. The Akuriyo language is now moribund with at most fifteen old speakers. Wayana who are inmarried with Trio and resident in the four villages also shift to Trio. ${ }^{16}$ 
The Aramayana and Okomoyana have been fully assimilated to the Trio and have been speaking Trio for many generations. ${ }^{17}$ According to informants there are only a few "unmixed" Aramayana since they have been intermarrying with the Trio for generations. It is likely that the Sakëta group, who locate their origin in Brazil, were always Trio-speaking. The only other reference to this group in the literature is in Findlay (1971:5) who states that Sakete (Sakëta) is a proper name, that of the leader of the group. Due to political tension in Kwamalasamutu, the entire Sakëta group, constituting roughly sixteen families, is at the time of writing, packing up to move permanently to Brazil. The Sikiyana appear to have migrated from the west and it is unlikely that they exist elsewhere now. ${ }^{18}$ Since nothing is known about the languages these groups spoke, it is not possible to tell if they were simply dialects or languages closely related to Trio. Oral traditions, as well as informants older than seventy, say that the languages were distinguishable but that the people were "just like the Trio."

The other groups, namely the Mawayana, Sirewu, and Tunayana have become acculturated Trio and have shifted to Trio. ${ }^{19}$ While there are some Mawayana in Brazil, the Tunayana do not seem to be represented elsewhere, thus their shift to Trio can be correlated with loss. ${ }^{20}$

While we will never know now what the languages of most of the groups given in Table 5 looked like, the fragmentary evidence, such as the few wordlists in Farabee (1924), indicates a group of related dialects or languages with differing degrees of distance. Present-day information, however, allows us to conclude that Akuriyo, in spite of a relatively high degree of lexical similarity is mutually unintelligible with Trio and may be considered a separate language.

Traditionally, at least since the time of contact, all the above-mentioned groups lived contiguous to one another and are found in the literature as separate groups who knew each other but who were not necessarily living in the same villages. Population movements resulted in new bonds of friendship based on a system of reciprocity, and an increased feeling of affiliation with the new group. This system is still in practice today and the relationship between the parties is expressed by the word pawana "(trading) partner, friend"; thus one enters into a relationship of mutual help by one person stating ji-pawana ëmë "you are my friend." The importance of friendship bonds based on reciprocity as well as the residence area over and above that of ethnic affiliation can be seen here as a determinant of both linguistic and social behavior (cf. Rivière 1969). 


\section{ETHNOHISTORICAL DEVElopmENTS}

The ethnohistorical data we have are scant. The problematic and perhaps one could say time-unstable nature of group names in South America in general and Amazonia in particular is well known and makes interpretation of the historical sources difficult. It is assumed that the present-day Trio consist of a conglomeration of several culturally and linguistically diverse groups (cf. Frikel 1957; Rivière 1969). This assumption would appear at first sight to be consonant with oral traditions according to which the first people were the Pirëuyana "arrow people" who mixed with other groups, yet at the same time it raises the question of how we are to interpret the historical data that are available, and it also raises questions as to how the so-called different groups fused to become what Frikel terms the "Trio group." 21 Nowadays there is linguistic homogeneity to a large degree in that all those in the Trio villages speak Trio, yet different fusion processes lead to different degrees of intergroup mix. The individual history of the groups bears on the sense of ethnic identities prevalent among the speech community today.

Little is known about the history of the Trio or their migratory patterns prior to the first reported contact in 1843 . The Brazilian missionary, Protásio Frikel, makes extensive claims in his reconstruction of the first inhabitants of the Guiana region basing these on both scant archaeological evidence and findings from the material culture. Frikel's claims lack not only a systematic scientific methodology but also linguistic evidence to underpin them and it is thus not entirely clear how he eventually arrives at his conclusions (Frikel 1957, 1961). ${ }^{22}$

Based on his study of Amerindian groups in the northern Pará region of Brazil and surroundings areas, Frikel claims that the name Trio is a generic term used to denote a conglomeration of Amerindians consisting of at least twelve sub-groups. These he divides up into six peaceful groups and six "wild" groups. The "wild" groups are those whom Frikel defines as having a "marginal stone-age culture" and who are described by the Trio and other peaceful groups as being ëire "dangerous." 23

The names given in Table 5 are all of groups that we encounter in the relevant literature over a period of two centuries. These groups were for the most part living in separate settlements and they had varying degrees of interethnic communication and interaction, be it peaceful or hostile. Linguistic evidence from early descriptions of the area, such as Schomburgk's, seems to point at a dialect continuum, that enabled these groups to interact. Farabee's later accounts tell of dances and festivals to which neighboring groups were invited, thus we can assume that there was some 
Table 5. The "Trio Group" after Frikel (1957)

\begin{tabular}{ll}
\hline Friendly subgroups & Wild subgroups \\
\hline Aramayana (Aramagoto) & Akuriyo 24 \\
Aramicho (Aramiso) & Kukuyana \\
Arimihoto (Arimiyana) & Pianoi \\
Maracho (Pianokoto) & Tiriyometesen \\
Okomoyana (Maipuridjana) $^{25}$ & Wama \\
Prouyana $^{26}$ (Rangu) & Wayarikure (Oyarikulets) \\
\hline
\end{tabular}

degree of mutual intelligibility. We also know that there was intermarriage between related groups and that a formal language register - in Trio known as nokato - was required in order to ask for a wife. It would thus seem to have been an arbitrary choice to take Trio as the group name and one wonders why Frikel did this. One possible explanation is that the Trio were the most numerous of the dialect group. A second possible explanation is that the Trio were more accessible to Frikel and in contrast to other groups perhaps more forthcoming with information. The information on extant and obsolescent groups that the Trio gave Frikel, and in more recent times myself, is always in relation to themselves, that is, they say other groups are or were "just like the Trio but speaking a different language" or "different from the Trio." But just how much integration or assimilation has occurred among these groups who are living with the Trio? My experience is that when one asks an Amerindian from Kwamalasamutu what ethnic group he belongs to, he will first say Trio. Only much later and after persistent questioning will he say that he actually belongs to another group originally. One reason for this may be that an outsider will know or have heard of the Trio whereas no-one until now has assumed that there are, for example, Tunayana living in Suriname. In the village itself one's descent is known and can often be guessed at by the location of one's house, that is, in all the villages, there are signs of ethnic cluster formation.

These ethnic clusters are also indicative of social stratification, and afford us some insight into the social and authoritative structures that have evolved in the settlements. When the missionaries began their work in the interior, they encouraged larger population concentrations at one or two bases, and the Trio flocked to these mainly to benefit from Western medicine. Thus all these groups who had previously lived at a safe distance from one another, each with their own leader/s, were thrown into an allochtonous construct of mass (!) populations. It would be surprising indeed if no conflicts in the domains of political and social authority were to arise under such circumstances. And they have. I do not intend to deal 
with the actual power struggles here, rather I give some options of how the Trio minimalize or at least oversee the conflict situation.

Since the focused settlements disrupted the one-village one-leader structure and now there may be between two and four village leaders, the conflicts that arise can generally only be solved by forming units within the village, or by one or other group moving away and setting up another village. Both options can be observed today. In a physical sense most groups live in clusters in the villages so that while one cannot talk of absolute clear-cut territorial boundaries, there are indications now of a return to segregation with for example a Waiwai cluster, a Katuena (Tunayana) cluster, an Akuriyo cluster, etc.

The other option is in progress, that is, apart from the Sakëta group moving to Brazil as stated above, a new village unit is being formed adjacent to Palumeu and a further village has just been established near Mount Kasikasima. This latter village was set up mainly at the instigation of an evangelist who had intended it as a bible camp and a meeting place for the Trio of Suriname and the Trio of Brazil to talk about matters religious. Due to the political unrest and dissatisfaction with the leadership that has been reigning in Tëpu for the last few years, many people saw the bible camp at Kasikasima as a welcome way-out, and decided to establish a new village there. ${ }^{27}$ The evangelist cleared an airstrip there with the help of the Trio from Tëpu, who are now busy building houses and clearing fields. The decision to stay there, however, has further exacerbated the internal conflicts in Tëpu with the general feeling that this action is splitting the village. Apart from political consequences and an obvious felt need to restore old structures, there are also practical difficulties involved in setting up a new village. These are the now basic facilities such as medical care and schooling. The new village, in December 1996 still referred to as kampu "camp," has an airstrip so that in case of emergency, the Missionary Aviation Fellowship (MAF) can fly in, and it has one radio for contact with the outside. There is, however, no well-trained medical assistant and there is no clinic, nor are there medical supplies. Nor is there a school for the children and even if and when the inhabitants build one the chances of managing to persuade a teacher from the capital to go to a village that is even more remote than the other more established villages and that totally lacks any kind of infrastructure qua authoritative power are extremely low.

That all these arguments against setting up a new village outweigh the dissatisfaction of the current situation at least in Tëpu, and if one takes into account that the Trio avoid conflict at all costs, usually by removing themselves physically from the confrontation site, is a clear indication both 
that the larger villages that were set up for evangelizing purposes are in the long run not very successful and that steps are being taken to find a solution to the problem. ${ }^{28}$

\section{POWER AND LANGUAGE}

The structure of authority in the villages is that imposed by the Suriname government, an authority that is referred to in Trio by the Sranantongo term lanti "government." The highest position is held by the granman ${ }^{29}$ who is assisted by two or three captains who in turn are assisted by three subcaptains, known as bashas. Trio does not have an autochtonous term for any of these positions. ${ }^{30}$ In addition, an overseer of the leadership "Bestuursopzichter" (BOZ) has been installed by the government in Kwamalasamutu, the present one being a Carib from the coast. In his 1981 report on the Trio, Rivière points out the difficulties involved in having state-appointed leaders. The present granman in Kwamalasamutu was, however, elected by the villagers and although a policy of favoritism is prevalent, he, along with the captains and assistants, does seem to have gained the respect of the majority of the population (Rivière 1981:23-26).

The present granman is also a prominent member of the church community; he preaches the sermon every Sunday, and he, and most of the captains, attend church every day for Bible readings. Thus there is much overlap in the church and village leadership, a trend that was recognized by Rivière (1981). It is questionable how much of or in what way the Christian message has been understood by the Trio, and the church is a meeting place also for secular affairs with the balance tipping towards the secular. ${ }^{31}$ There seem to be few conflicts arising from church matters while, in general, village and personal conflicts do arise. Moreover, it does not seem to be the case that exemplary behavior is expected from the leadership since there is no discernible difference in social or moral behavior between the village and church leadership on the one hand and the rest of the villagers on the other.

The leadership is responsible for the status quo in village life. It acts as a mediator in conflicts and metes out punishment to wrongdoers. ${ }^{32}$ Any outsider wishing to enter the Trio villages requires approval from the leadership. Thus visitors are obliged to present themselves to the village leadership, stating their intentions, the planned length of their stay, and asking permission to stay there. In Tëpu, however, where I started my fieldwork, the leadership consisted of three captains, one of whom was absent, and three bashas. Thus in a meeting that was scheduled for the day 
after my arrival, I had to address "the leadership." About three quarters of an hour into the meeting, when I thought I had given a detailed outline of my intended linguistic work, from the phonetics through to complex verb forms, one of the captains spoke. The interpreter translated saying "this captain says that's all right, now this captain wants to know what you want to do here." I heaved a sigh of relief that the third captain was temporarily in another village, and started all over again. The meeting lasted two hours. If one considers that the traditional village had one leader who was addressed directly, by Trio visitors in a register of Trio known as nokato, then the above occurrence is not surprising; thus I too was seen to be addressing one captain at a time. Before the larger settlements were set up, a typical village had one leader who was referred to by the term pata entu or pata i-tamu, "place (village) owner" and "place (village) its-leader." 33 Tamo is the term of address to an old man, and signals respect, not only for his years but moreso for the wisdom he has acquired. It is also the case that villages were often named after their leader, for example, Simëtu $i$-pata "Simëtu's village." 34

The leadership may accept or reject strangers, and acceptance of a stranger into their midst entails carrying responsibility for the visitors' or strangers' well-being. Such is the case with the settling of Akuriyo in the village of Tëpu. The Akuriyo were (literally) taken from the forest and planted among the Trio in Tëpu by missionaries in the late 1960s and early 1970s. In doing so the Trio in general and the leadership in particular were made patrons of the Akuriyo.

The Akuriyo are one of the "wild" Trio subgroups of Frikel's description. ${ }^{35}$ They were the last of the Amerindian groups in Suriname to leave their nomadic way of life in the forest and they are now settled among the Trio - there are at present about thirty-three in Tëpu, about ten in Kwamalasamutu and one or two in Palumeu. From the outset they were brought in as poor "lost souls" to live among and learn (mainly about God) from the Trio. The price, however, was high since they were not accepted as being socially on a par with the Trio. Apart from the high number of deaths that occurred shortly after arriving in Tëpu there came a break in transmission of the Akuriyo language as the children learnt the language of their peers, Trio. The result is that all the Akuriyo are Triospeaking and that their former language is now moribund. While they acculturated linguistically, their social status vis-à-vis their Trio patrons remained low. The Akuriyo are greatly respected for their knowledge of the forest but their present position in the villages is that of total subjugation, they are de facto servants of the captains in particular and of the Trio population in general. Furthermore, while intermarriage with the 
other groups does exist, it is perceived as undesirable to intermarry with the Akuriyo. In contrast to the attitude of the Trio towards white people and researchers, which could be termed hesitant, the Akuriyo are actively interested. On hearing that I was interested in their language, I promptly had a thirty-year-old Akuriyo at my house, armed with his notebook and his father, who spoke the language, asking me to make recordings. I gladly obliged but the incident was reported to one of the captains who summoned me to his house and pointed out that I was not to work with the Akuriyos without his express permission or without an appointment being arranged through him.

This attitude of superiority can also be detected in other spheres of life, namely in the Trios' attitude towards their own language. The intra-ethnic (Tarëno and Tarëno-ton) attitude towards Trio is a positive one. Trio enjoys high status and is dominant. Given a wider setting, however, a somewhat ambiguous stance becomes evident in that the Trio do not consider their own language to be a worthy subject or medium of instruction in school. Thus there are for them languages with higher prestige, namely European languages. ${ }^{36}$ Trio is the language spoken in all domains that are relevant in this society such as home, school, church, and administration. The music of the hymns sung in church is of European origin while the words sung are Trio. The language of the classroom is officially Dutch, and that of the "playground" among peers is Trio. Among themselves, the guardians of the Trio language are the older men and storytellers. I heard from these on more than one occasion that most of the younger men no longer speak "good" Trio but that they speak differently from the older men. Furthermore, those who lived for a longer period in town as well as children of mixed marriages, even though they are Trio speaking, are not considered "good" speakers of Trio. Thus ancestry and ethnic group identity are clearly reflected in a subjective "purity" of the language. Although the Trio have a wealth of oral literature, storytelling does not seem to figure prominently in their society. It is not clear if it ever did play an important role nor did the sessions I had with the most renowned storyteller, Tëmenta, attract any listeners.

Language is a powerful weapon in any society and the awareness of this fact is prevalent among all Trio. It is by means of language that a person can show his inner strength, his leadership qualities, and it is also, though not only, by means of language that a person can be cursed, even over a distance. And it is by its inverse, that is, silence that one can equally make a point, namely by walking away from a conflict. ${ }^{37}$ When a stranger comes to a village he is judged by his language, not only by what he says 
but also by the way he says it. As mentioned above, strangers to a village traditionally introduced themselves by means of the ceremonial dialogue, nokato, which was also used in order to ask for a wife and to trade. This verbal display was used an indicator of the character of its producer. Strength in this verbal art was highly regarded and both showed respect for the village authority and generated respect for the visitor. The nokato is a formal discourse register that had to be learned. This type of register was referred to as ceremonial dialogue by Fock (1963) in his description of the Waiwai and taken over by Rivière $(1969,1971)$ for the Trio. It is deviant from normal spoken Trio both lexically and morphosyntactically. Rivière differentiates two types of ceremonial dialogue, namely tesëmiken ${ }^{38}$ and turakane which can be distinguished according to their function and the role of the participating parties, with only the latter being competitive in nature. Tesëmiken was the least formal type of ceremonial dialogue and could involve two or more participants, male or female who were related or acquainted. It was mainly used to tell people of one's immediate plans or to relate something out of the ordinary that one had done, or it was used between people who had not been in contact with each other for a while. It was characterized by the fast speed at which it took place and it required the listener to reply at intervals with irërë "so it is." On the other hand, turakane, which is derived from the verb ëturaka "to converse, talk business, do barter," was competitive and a test of one's verbal skills. Turakane is subdivided into the very formal nokato and the somewhat less formal sipësipëman. ${ }^{39}$ It was used by a stranger arriving in a village, to assure the leader of his good intentions, to conduct trade, and also to ask for a wife.

The strongest and most formal of this type is nokato which is used only by men, mostly older men, who sit on stools facing slightly away from each other. A nokato session could last from 5 p.m. one evening till even later the following evening. Rivière (1971:299) states that a man and woman can use this form but not women among themselves. Nokato is characterized by the two participating men taking turns to speak approximately every ten minutes. This form is almost sung rather than spoken. The sentences are short and end in kara or taame. The listener responds with a low murmuring grunt. The language used in the turakane is archaic and stylized. The response is sometimes a grunt and sometimes irërë "so it is" or aerë "really." In the sipësipëman, it may also be a confirmation of what has been said, for example ëmërëken "only you" in reply to wïrëken "only me." Unfortunately not a single form of the ceremonial dialogue is in use any longer. It has already become obsolete. The significance of the loss incurred - since it is not just these registers that no longer exist - is 
indicated by the lament of one elderly speaker according to whom there are no tamu "elders" left any more, only muretiton "children," not in the physical sense but in the sense of wisdom, knowledge and character. ${ }^{40}$

On an equal footing with the words one uses is pitch, tone, and loudness. Loud speakers are treated with both disdain and fear. If a person is a loud speaker that is the first attribute that is mentioned when the Trio describe him/her and it is not a positive one. The Trio have an aversion to and seem to be totally intimidated by loud voices. Considering the fact that the Trio themselves and most of the other groups living in their villages, with the possible exception of the Wayana, are extremely softspoken people, who can communicate over large distances with a barely audible whisper, it is not surprising that most Creoles and whites are classed as loud speakers. Furthermore, the Trio language lends itself to whispering because there is no voice opposition, that is, speakers can whisper without neutralizing a possible distinction between voiced and voiceless obstruents. ${ }^{41}$ However, it is not only loudness that should be avoided but also overuse of grammatical imperative forms since these signal impatience and an assumed superior attitude on the part of the speaker.

Power play is also evident in the dialect distinctions that are made. Two dialects can be distinguished in Trio, namely, what can be called the western dialect spoken in Palumeu and Tëpu and the eastern dialect spoken in Kwamalasamutu and Sipaliwini. ${ }^{42}$ The distinctive features which mark the differences in the dialects are mainly phonological in nature so that the western dialect has $/ \mathrm{k} /$ and $/ \mathrm{p} /$ where the eastern one has $/ \mathrm{h} /$ and $/ \beta /$ respectively. There are also grammatical and a limited number of lexical differences.

While the differences between the dialects are not major, the fact that there is a difference at all is of paramount importance for many speakers. The result for someone like myself learning Trio is that one has to adapt one's speech according to the village one is in since it is very easy to offend the Trios' sensibilities on this matter. One example of stepping on toes is a recent evangelical publication which was translated by a Trio from the western dialect. Those of the eastern dialect refuse to use the booklet saying that it is not their language.

\section{CONTACT AND CONTACTING LANGUAGES}

The relations obtaining between the ethnic group Trio and the state are characterized by a mutual lack of understanding. Suriname does boast at least two organizations which were set up to represent the rights of the 
indigenous peoples of the country. These are run mainly by coastal Caribs, and although they include the groups of the interior in their fight for their rights, there are no Trio representatives on the board of decision makers, and there is good reason to doubt that the coastal Caribs or Arawaks, whose socio-cultural background differs vastly from that of the groups of the interior, understand or can even realistically represent these people. Thus we see that the Trio can be regarded as a more or less autonomous socio-political entity whose contacts with the state and groups from the coastal region are primarily initiated by the latter. On the macro level we look in the following at the status of the Trio language and the domains in which it is used as well as general attitudes towards the contacting languages Sranantongo and Dutch.

There is little continuity in contact with the outside world. Only few Trio live in Paramaribo, one major obstacle being the costs they incur there, in particular food and housing costs. A visit to the capital usually entails returning to the village tïwirijehpëtae, with one's "vertebrae visible," that is, thin as a rake. This is, however, not to say that many young people would not like to go to Paramaribo. There are both linguistic and cultural reasons that hinder them, namely, their lack of knowledge of Dutch which is necessary in dealing with the authorities, and their imperfect knowledge of Sranantongo, the lingua franca, which hinders their social mobility.

The only townspeople living in the Trio villages are the school teachers in Kwamalasamutu and Tëpu, the two villages with more or less functioning schools ${ }^{43}$ The teachers are almost all Creoles formerly in church and now in government employment; they have inadequate or no knowledge of Trio. In 1995 the American Peace Corps set up a base in Tëpu. One trained nurse from Paramaribo is resident in Kwamalasamutu and is assisted by four Trio, in the other villages, the medical staff consists only of Trio nurses some of whom have been trained in town. Directly beside the village of Palumeu there is a tourist resort run by the METS, an eco-tourism company. They have at least three permanent staff there from town and a relatively steady influx of tourists. Between thirty and fifty villagers are in paid employment with the METS, but it is generally only the barmen and the boatsmen who have any contact with the tourists. On average there may be a group of about ten tourists a month who on one day of their five-day trip are guided through the village itself. These are for the most part completely ignored by the villagers who continue with their daily tasks, apparently not even directly looking up to inspect the tourists. ${ }^{44}$

Since the Suriname government upholds an exoglossic language policy with Dutch as the official language of the country, all official administration, as well as the educational system, is in Dutch. Trio, and also the 
other languages of Suriname, have no institutional status whatsoever, they are not taught in schools neither as a medium of instruction nor as a subject.. Hence the social function of the Trio language does not extend beyond the bounds of the Trio settlements and Trio society may be seen to constitute an autonomous entity vis-à-vis the "national" construct Suriname. External contact with the main body of the Suriname population, government officials and traders, is carried out mainly in Sranantongo. Beyond these domains, Sranantongo is of limited use in the eyes of the Trio. Teaching through the medium of Sranantongo in school is not a desirable option, nor does Sranantongo carry any of the prestige that Dutch does. As a consequence of this language attitude the Trio are not fluent in Sranantongo, (nor in Dutch); official dealings with the national authorities are conducted with the help of interpreters..$^{45}$ Although some of the village captains understand Sranantongo and may even speak it, it appears to enhance their position of authority vis-à-vis the government if they use an interpreter, that is, respect is strived at by means of language. The interpreters are, as a rule, assistants chosen by the captains, and are those young men who have either spent short periods in Paramaribo or who were in the past in close contact with non-Trio in the villages.

Many Trio and in particular the leadership in Tëpu and Kwamalasamutu, fought to have Dutch as the medium of instruction in schools, and this is indicative of the prevailing positive attitude towards Dutch. ${ }^{46}$ It is generally seen as desirable to have a good knowledge of Dutch, and being the only European language (i.e. language of the white people) in that area, it is regarded as being the one language that can potentially open the door to economic enhancement and upward social mobility. The schoolchildren, however, keep their use of Dutch to a minimum and if an answer is forthcoming at all, they often answer the teacher in Trio. As a consequence, education is more geared towards learning Dutch than acquiring general knowledge. Furthermore, a lack of understanding of the general culture of the indigenous society thwarts any attempt be successful in teaching or to prepare the Trio for immersion into the larger society.

With the advent in the last years of Americans, mostly missionaries, and English-speaking Canadians, mostly forestry and mining company officials, and influenced by the fact that some Trio individuals have been taken to the United States by at least one of the missionaries in order to work on a bible translation, English is now vying with Dutch to be the most desirable language to learn. What I have given above is simply the "attitude" of the Trio towards Dutch (and English). In practice few steps are taken to realize the ideal situation of being competent in a European language.

Thus formal education takes place in Dutch. Since children starting 
school generally have no knowledge of Dutch beforehand, the process of learning to read, write, and count takes place in a language that is not only totally foreign to them but also a language that they have no recourse to outside the four hours of school a day. This is in sharp contrast with the situation that prevailed two decades ago when Dutch missionaries started an alphabetization program in Trio, and taught both Trio and Dutch. The present generation of thirty to forty-five-year olds bears witness to that teaching and although they now, due to lack of practice, no longer speak fluent Dutch, they can read and write Trio. ${ }^{47}$ Because the Trio are very mobile and often travel to other villages, those wishing to contact relatives take the opportunity to send written messages in Trio with the travelers. At the same time, and probably due to their lack of general education, the Trio do not know how to implement the teaching of a foreign language. The general consensus among the Trio, and especially among the leadership, is that if it were at all possible, the Trio would give up their own language in order to be Dutch speaking, that is, they do not see the possibility of learning Dutch alongside their own language. In my initial meeting with the village leadership in Tëpu, for example, it was stipulated that if I were going to write a book about their language I would have to do so in Dutch (or English) so that the Trio could learn that European language. Koelewijn's 1984 collection of their oral literature, published in Trio, is in their eyes totally useless, since they say they cannot learn anything from it, yet the English translation published in 1987 is inaccessible since they have no knowledge of English. ${ }^{48}$ They do not regard their own language as being a worthy subject or medium of instruction in schools.

Contact opportunities where the Trio are required to speak another language do not arise very often and when they do, they do not affect the lives of most Trio who are for the most part economically and geographically independent or isolated. I consider below a few salient points of Trio economy in order to contextualize the type of contact situations that arise, and I refer the reader to Rivière (1969 and 1981) for a detailed description of Trio culture and the impact of economic changes. The few Trio who are in paid employment include the village authorities, the medical staff, and those who are paid to mow the grass and keep the airstrips in order. In the case of the captains, their salaries are paid into a bank account in Paramaribo and every few years the captains are flown into town to collect it. The salaries paid are, however, nominal and much more money is earned by younger men catching birds or animals for a few animal traders who fly into the villages at short intervals. Those who have connections in the capital often send birds themselves to be sold privately. In addition, there are outlets in Paramaribo and in Palumeu for the sale of tourist 
items such as necklaces, combs, rattles, and miniature bows and arrows.

Palumeu forms an exception in the sense that the tourist company METS employs both Trio and Wayana in their resort as kitchen staff, boatsmen, and gardeners. There has, however, not been a significant effect on language use among the Trio of Palumeu: there is no greater proficiency in Sranantongo or Dutch among the Trio there compared to those in Tëpu. There has been a more obvious effect on the younger generation as regards their form of dress and some "modern" habits such as smoking, the latter of which is frowned upon by the older generation. Furthermore, Palumeu is often seen as a stepping stone on the way to town.

Even if one is in paid employment, however, there is limited use for money in the villages themselves since even if there is a shop the price of goods sold there is exorbitantly high, indeed it has to be in order to cover the freight costs. ${ }^{49}$ Apart from this reason, the Trio are not adept at buying and selling for money, rather their tradition is one of bartering and they find it difficult to assess or appreciate the monetary value of an object. 50 The numbers in Trio are borrowings from Dutch. Moreover, transactions only affect modern non-cultural goods, and indispensible commodities such as foodstuff are not to be sold or even bartered, a painful fact that this researcher was confronted with as I got thinner and the thousands of fish hooks I had brought with me to exchange for food, enough to catch all the fish between Suriname and the Mediterranean, remained in my bag. This is not to say, however, that the Trio did not want or need fish hooks, on the contrary, but they would have preferred them as a gift.

In view of the fact that the Trio live in remote areas and are relatively self-sufficient, they have no intense contact with non-Amerindians. There is practically no supervision by the central government, and politicians only tend to remember the Amerindians of the interior when there are national elections and votes are needed. However this attitude rests on a mutual understanding and the Trio can move around, establish new villages, and maintain law and order themselves without involving the central authorities. Thus we see here a high degree of autonomy, with Trio the language of the "local" government.

\section{HISTORY OF CONTACT}

Contacts in the past were of a different nature and an entirely different, now obsolescent, contact language was used, namely a pidgin based on Ndjuka and Trio. But first a general word on the history of contact and on how the Trio were met and perceived in the past. 
During the eighteenth century the general name for the Amerindians of the interior was Akouri (Acouri, Akuri, Akolie). It can be assumed that the Indians on the coast and the Creoles were aware of a group of Indians called the Trio in this century. In a report to the governor in 1796, F. Meyer writes of "a sort of Akolie called Trios" who had been warded off in an attack. ${ }^{51}$ While this incident can also be regarded as a type of contact, the first report of a less physical kind of contact with the Trio was by the explorer Robert Schomburgk who, in 1843 after great exertion, came upon a village of "Drio" near the head of the Cutari River who were living in a settlement at the source of the Wanamu and whom Schomburgk (1845:84) classified as a "sister tribe of the Pianoghotto." 52 Schomburgk (1845:86) does not describe the Trio in any great detail but simply states that they looked very much like the Pianoghottos in their dress, their manner of painting their bodies, and their general rather "ghastly appearance." When they first sighted the white expedition, in canoes on the river, the Trio had fled in fear. After ascertaining that the intruders were not dangerous, the Trio were, at least initially, more curious than afraid to meet them and afforded them great hospitality. That the Trio did not totally trust the whites is evident from the fact that on the morning of Schomburgk's departure, when he went to bid them farewell, he found that they had already fled the settlement. This was, however, not before they had generously provided Schomburgk's expedition with food for the ten-day journey that lay before them. Schomburgk does not provide us with a detailed account of the Trio, but he does mention that they were in contact with the Maroons and that they considered themselves to be their "matties" or friends.

The next reported contact between the Trio and Europeans was in 1878 when the French explorer Jules Crevaux met a few Trio on the upper reaches of the East Paru. Crevaux's encounter with the Trio, however, was not as felicitous as that of Schomburgk. On arriving at a village called Aracoupina, he met with a sombre picture that he describes as follows: "Toutes les maisons sont désertes et au milieu on remarque un enfoncement dans la terre: ce sont les sépultures d'un grand nombre d'Indiens" (Crevaux 1883:275). Two of Crevaux's assistants were sent to scour the environs for the inhabitants and soon returned with a couple. Crevaux's proffered gifts were refused by the woman who pointed to three freshly dug graves and said: "Panakiri ouani oua, a la pikininialele, nono poti. Echimeu ouaca, cassava mia oua" which translates as: "we don't want whitemen; all the children are dead, put in the ground. Leave quickly, don't eat cassava." 53 Upon which the woman and her companion turned and left. Crevaux attributed the deaths to a smallpox epidemic. ${ }^{54} \mathrm{~A}$ certain 
degree of apprehension is still present today when strangers arrive in Trio villages and it is not unusual for a visitor to be asked: otono menee? "have you brought the cough?" Besides giving us the above short discourse, Crevaux (1882:39-40) provides a Trio wordlist of twenty-nine entries which, with a few exceptions, is identical to later wordlists and presentday Trio. Perhaps the most interesting thing about Crevaux's encounter with the Trio is that the woman addressed Crevaux not in Trio but in the pidgin that was used in trade negotiations with the Maroons, namely the Trio-Ndjuka pidgin as described by De Goeje $(1906,1908)$ and more recently by Huttar and Velantie (1997). .55

In the first decades of the twentieth century, the Dutch carried out three exploratory expeditions to the area which were documented in detail by Franssen Herderschee (1905), De Goeje (1906, 1908), and Käyser (1912) and it is from these writings that we get a fuller ethnographic description of the Trio and also a better idea of their language. ${ }^{56}$ The wordlist provided by De Goeje (1906) contains 509 entries, including some short sentences. Käyser included a wordlist of 187 entries in his report (Käyser 1912:509-14). In 1916, the American ethnographer Farabee made a trip following the same route as Schomburgk. Apparently unaware of the Dutch expeditions and the linguistic material collected by De Goeje, he found the Trio, whom he calls the Diau, living in the same area where Schomburgk had found them. That Farabee's Diau are in fact the Trio is evidenced, in spite of the somewhat idiosyncratic transcription, by the 152 item wordlist he provides (Farabee 1924:208-11).

Later meetings include a Brazilian expedition under General Rondon in 1928, who met with some Trio on the Marapi (Rivière 1969:13). In 194042 Lodewijk Schmidt visited all the villages inhabited by the Trio in order to gain a general picture of the population numbers and conditions prevailing in the southern border region of Suriname. In 1948 Protasio Frikel, a Brazilian missionary, entered the Trio area and over the following two decades made a study of their linguistic and ethnic affiliation. ${ }^{57}$ In 1959, a Catholic mission post was set up near a landing strip at West Paru in Brazil. A year later, as a result of Operation Grasshopper, an initiative taken by the central authorities to make the interior more accessible by cutting some airstrips, and for which purpose they used American pilots, an American Door-to-Life Gospel mission was set up at Palumeu in Suriname, followed shortly after by a post in the Sipaliwini basin (Vernooij 1989:127ff).

By 1963 when Rivière embarked on anthropological fieldwork among the Trio it was clear that intensive contact with the evangelizing forces had had a devastating effect on the cultural autonomy and heritage of the Trio in Suriname. Many traditional practices had already at that time 
fallen into disuse. Besides banning dancing, drinking, and smoking, an end was put to the practice of shamanism and church services according to the Christian model replaced traditional methods of contact with the spirit world. The spirit body wiripee, an ambiguous and thus not inherently evil spirit, was assigned the role of Satan in the translation of the New Testament. One of my informants, who was diagnosed as having epilepsy, insisted that he had wiripe ë in his head. By having redefined the term to Satan, and even if this man is not a practicing Christian, the doubts as to the true identity and purpose of wirïpe are sufficient to have a negative psychological impact on him. Moreover, the Trio were taught that their native practices were primitive and that they were poor, ignorant, and to be pitied. When my informants were referring to the pre-missionary days, they insisted that in those days they were like the Akuriyo of today, poor, ignorant, and to be pitied. When collecting texts from older informants, most references to imported concepts such as giving names to each month of the year, were accompanied by comments such as "pena inkutuntëewa witoto ... kepeerewa mëinjarë nai awaintao irantato" "long ago the people didn't count ... but now the year (thing) is out in the open, i.e. has been revealed, and now we know about it." 58 One major result of missionary contact was to reduce the mortality rate, that is, the Trio, as well as other groups in the interior, in the late 1950s and early 1960s were fighting various diseases, among these influenza and colds. When the missionaries brought in medicines to treat these, their positive results lent force to their message of evangelization. Thus, when the Trio, threatened with decimation, heard of the medicines the whitemen had, it was they who moved house in order to benefit from this. The result is that now it is not unusual to find up to four generations of one family living together. ${ }^{59}$

While the contacts described above may seem numerous, they do not offer us any continuity nor indeed much linguistic or historical information. What we do learn from these reports as well as others is that the Trio were met as a group separate from those groups that are now said to make up the group such as the Okomoyana, Sikiyana and others. It would seem that there may have been two reasons for the later Trio dominance, namely their numerical strength and the advent of the missionaries who used Trio as the medium for evangelization.

One group we do know had regular contact with the Trio is the Ndjuka, a Maroon group living along the Tapanahoni and thus geographically the most proximal trading group, with whom the Trio upheld a trading relationship in the past for upwards of two centuries. ${ }^{60}$ This trading was conducted in a stable pidgin which now has been replaced by Sranantongo. Some older men still remember the pidgin, not as a productive sys- 
tem but rather as a set of formalized utterances. ${ }^{61}$ It is not clear if the use and knowledge of this pidgin was restricted to a few Trio trading on behalf of an entire village. Huttar and Velantie (1997:103) state that this pidgin is not confined to trade but that it is used for general conversational purposes between the Trio and the Ndjuka, as well as between the Wayana and the Ndjuka. Thus it may well have been a general contact language; Crevaux was addressed in this language by a Trio woman. The younger Trio no longer speak the pidgin and now use Sranantongo also with the Ndjuka. Huttar and Velantie (1997:103) likewise state that "many Ndyuka men in their 30 s (perhaps even older) and younger do not know it [the pidgin]." The trading parties who used this pidgin also had a somewhat different status from the present-day traders. Although the Maroons, also in the past, drove a hard bargain, they were considered to be "friends" of the Trio and they had initially entered into a reciprocal exchange that was marked by drinking each other's blood. The presentday Creoles are not regarded as having entered such a bond of friendship and while they may not be feared as much as they used to, they are certainly not highly regarded.

Thus there is no particular interest on the part of the Trio to intensify contact with the Creole population. That said, there have been unavoidable influences, especially on the Trio language. Although there is very little lexical borrowing into Trio, most of the loan words they have stem from Sranantongo, and to a lesser extent from Dutch. ${ }^{62}$ Borrowing is generally employed to encode notions foreign to Trio culture, a factor to which we may attribute the fact that in the multi-ethnic villages, there is very little evidence of lexical borrowing or indeed interference between the different Amerindian languages. In Kwamalasamutu, however, it would appear that the influence of a large number of second language learners has contributed to a tendency towards simplification or transparency in grammatical forms in Trio. To take just one example, we can observe how the ventive verbal imperative suffix emiii as in ene-miii < see-ven.imp "come see!" is now generally being replaced by the more transparent construction ene oh-kë < see come-imp "come see."

Most counting systems are from Dutch, that is, the Trio numerals are now being replaced by Dutch; the days of the week and months of the year are from Dutch. The numerals are assimilated to the phonological structure of Trio where the Dutch structure differs, inadmissible consonant clusters in word-initial position are avoided by the insertion of $\ddot{i}$, e.g., twee "two" is realized as /tiwe:/, drie "three" as /tiri:/. Table 6 gives the original Trio numerals. 63 
Table 6. Trio Numerals

\begin{tabular}{lclc}
\hline Numerals & Gloss & Numerals & Gloss \\
\hline teinken & 1 & itamume & 6 \\
akoron & 2 & ipëkërëme & 7 \\
ëirau & 3 & enturatëeme & 8 \\
epima & 4 & iwatihkame & 9 \\
einjame & 5 & naka iwehtome & 10 \\
\hline
\end{tabular}

The Trio have a quinary numeral system, with "5" einja-me "hand-adj" literally "being a hand." 64 The numerals 6 through 10 are morphologically complex forms for example, " 6 " $i$-tamu-me "3poss-leader-adj" i.e. "its leader," which is the short form for einja akoron i-tamu-me "second hand its leader" i.e. thumb of the second hand. "10" naka i-weh-to-me which literally means "finished 3poss-be-nom-adj," i.e. "its being is finished." Counting starts with the pinkie of one hand and continues on the second hand with the thumb; when counting, the hands are splayed with the palm facing downwards. While the numbers $1-5$ are still used in Trio by some speakers, they prefer to use the borrowed forms from Dutch for all numbers over 5. While some speakers use borrowings from Dutch for the days of the week, generally these are borrowed from Sranantongo. The days of the week are given in Table 7.

Table 7. Days of the Week

\begin{tabular}{lll}
\hline Trio & Phonetic & Sranantongo \\
\hline monri & monsi & munde \\
tureoroko & tureoroks & tudewroko \\
rireoroko & fireoroks & dridewroko \\
përeoroko & pareosoko & fodewroko \\
përera & parera & freyda \\
satertak & sa:tətak & satra \\
sonre & sonsi & sonde \\
\hline
\end{tabular}

The following are some borrowings from Sranantongo:

$\begin{array}{ll}\text { sopu } & \text { soap } \\ \text { soutu } & \text { salt } \\ \text { empi } & \text { shirt } \\ \text { pïrastiki } & \text { plastic bag } \\ \text { oroko }^{65} & \text { work } \\ \text { koiri } & \text { stroll, walk }\end{array}$


The last two entries are verbs in Sranantongo but are borrowed into Trio as nouns which are then affixed by the adjectivalizing suffix -me while the subject is encoded on the verb "be," e.g., orokome wae < work-adj. I.am "I am working" and koirime wae < walk-adj. I.am "I am strolling around." Most younger Trio speakers are not aware of the fact that these are borrowings from Sranantongo. While there is no corresponding verb "work" in Trio, there is a vernacular verb "stroll around," namely the intransitive verb root urakana, 1st person jurakanae "I am strolling around" which now, at least in Kwamalasamutu, is falling into disuse.

Words borrowed from Dutch:

paterai < Dutch batterij refers to both a battery and by metonymic extension to a torch, the most important item requiring a battery since the Trio now use torches to hunt at night.

The Dutch word peer is a bulb. Bulbs are needed for the torches.

Portuguese/Spanish sources:

karakuri money

kamisa loincloth

Not all new concepts, however, require borrowing but may also be encoded by means of new coinages. Two basic principles underlie word coinage in Trio, namely size and movement. The size criterion is used to indicate concepts from modern technology that are larger than comparable existing concepts. Some are taken from the animal world when the new concept involves movement and the goal concept is imitative of the movements made by those animals. The base concept is suffixed by the augmentative suffix -imë, for example:

pïjankëkëi millipede

pïjankëkëi-më train

pïmokoko libelle

pïmokoko-imë helicopter

Another concept is the word for airplane which is based on the same principle of augmentation, namely:

kanawa canoe

kanawa-imë canoe-big, airplane (small 1 and 2 motor airplanes)

Jumbo jets have only been seen by a few Trio but they are regularly heard flying overhead. These airplanes are referred to as kapuman < kapu-me-n "sky-adj.-nominalizer," literally, "one as the sky." 
The lexeme parataimë (balata "latex") can refer to a range of non-cultural objects generally made of a non-natural fibre, especially plastic. This balloon, bucket, and (leather) soccer ball are all designated by this term.

\section{CONCLUSION}

In conclusion the above profile reveals a language situation of stable maintenance of a minority language. In the past the Trio, not any more significant a group than any other in the region, absorbed other groups which resulted in an expansion of its speech community. Thus what we regard as the Trio speech community does not necessarily coincide with ethnic descent. We saw that vis-à-vis the state the Trio have retained a high degree of autonomy while taking advantage of any material benefits they can get from the central government, such as fuel for a generator, foodstuff, and clothes. From a structural linguistic viewpoint, Trio is dominant and in a strong position with few borrowings and a tendency to coin terms for foreign concepts. Culturally, however, much has been lost that can never be restored such as the ceremonial dialogue. ${ }^{66}$ The pidgin used for trading with the Ndjuka has likewise been lost and replaced by Sranantongo. All in all the Trio language is still in a strong position and is ousting other minority languages such as Akuriyo.

In spite of the low number of speakers, approximately 1,500 , it should have become clear by now that the Trio language is in no immediate danger of obsolesence, that is, it is not always or only the size of the speech community that plays a decisive role in determining its demise or growth, rather as we see in the case of the Trio, geographical, political, sociological, psychological, and linguistic variables may tip the balance in favor of survival. The geographical setting assures the Trio of fewer external contacts and a certain degree of political autonomy. The social structure that has evolved affords the Trio language and culture a dominant status in a polyethnic setting, thereby producing a strong ethnic self-identity that is reflected in language attitude and language use.

There are, however, certain factors that may still radically change this picture, namely if a large-scale migration to town should take place. Accessibility is now easier and younger men feel the desire to travel. In addition to this, traditional means of providing for a family in the interior, that is, hunting and fishing are losing their attraction since it is much easier to have a sack of rice flown in by the government than spend two or three days hunting in the forest with the dangers that lurk there. The transmission of survival techniques that were passed on from father to son has 
waned, especially in those families who have the Akuriyo hunt for them, and certainly among young men who spend a longer period in town, so that there is a marked decline in the required skills. Two other more immediate factors are the intrusion by goldmining and lumber companies and their workers and illnesses such as Aids. The former are already close to the Trio settlements and one can only hope that political measures will keep them at bay, the latter has been diagnosed as having been the cause of death for at least one young Trio in Brazil and a few others have tested positive for HIV. One is sadly reminded of Crevaux's experience in 1878 when on arrival in a village, the first thing he saw were graves and the Trio had fled. One can, however, be sure that no-one will ever address any whites again in the pidgin that Crevaux heard since that too belongs to a long forgotten episode in the history of the Trio.

\section{NOTES}

1. The data presented here were collected during a three-month fieldwork period (October-December) in Suriname in 1996. I would like to thank the Netherlands Organization for Scientific Research (NWO) for providing me with funds to carry out this research. For their valuable help and suggestions I would like to thank Maarten Mous, Mechthild Reh, and Peter Rivière. I am deeply indebted to the Royal Institute of Linguistics and Anthropology in Leiden for affording me a Visiting Fellowship from February until December 1997 allowing me the use of all their facilities during the writing of this paper, and for financing in part my second fieldwork trip (December 1997-February 1998).

2. The term non-unique minority language refers to the fact that a language is a minority language in more than one country. It contrasts with unique and local-only situations. For these terms, see Edwards 1992:38.

3. Decision-making on a local level is tolerated and perhaps even encouraged by the central government but political decisions regarding land rights and handing out concessions to lumber companies are made by the central government.

4. The Trio build their own houses, hence it is unheard of for Amerindians to have to pay for accommodation in their own villages. It is, however, expected that nonAmerindian visitors in a village pay for their lodgings, less so because it is the usual thing to do, rather because it is a means of ensuring that visitors leave money in the village.

5. The Surinamese Trio, and in particular those of the two southernmost villages Kwamalasamutu and Sipaliwini, have steady contact with the Trio of Brazil and often spend longer periods in Brazil. There are many cases of some family members living on either side of the border.

6. According to the Trios' own reports they intend to stay there with their families to monitor the activities of foreign lumber companies. Just south of Amatopo there are old burial grounds of the Waiwai and possibly of other Indian groups too. The 
report goes that as soon as there is any infringement upon the burial grounds, an army of Trio will spring into action.

7. For the most part in this paper, I refer to the Trio villages and the Trio speech community since, with some exceptions that I point out where relevant, Trio is the primary language in all the settlements. Thus the discussion of ethnic descent does not change the synchronic picture of a relatively homogeneous speech community.

8. The numbers given are approximations, based on my own observations and information from informants. Note that the numbers refer to ethnic descent and do not necessarily coincide with the numbers of speakers for groups other than the Trio.

9. In the early 1960s an American missionary set out from Guyana with some Mawayana and Tunayana who had been living there among the Waiwai, to evangelize the Trio in Suriname. It is not clear whether there were any Waiwai at all in the party. Since they all spoke Waiwai, that is the name that stuck, and the one that even today the Trio give these groups. Thus the people to whom the Trio refer in Kwamalasamutu as Waiwai are in fact Mawayana and Tunayana. The Trio seem to be unaware of the name Tunayana and refer to that group as Katuena with the result that some people refer to themselves as Katuena-Tunayana. As far as I could ascertain by means of wordlists Tunayana and Katuena are one and the same.

10. An exception is, for example, Sakëta which is a proper name of a village leader.

11. The -no in Tarëno could possibly indicate an agentive nominalized form of a verb, i.e. "one who ...."

12. Rivière (personal communication) has rightly pointed out that it is difficult to assess how old this term is since it is not referred to in either the ethnographic literature nor in the oral texts that are available (Koelewijn 1987). Since pirop it is a descriptive term, however, and as such not an ethnonym, I have included it in the present paper. Whatever the reasons for the lack of references to this term, it is certain that the Trio do clearly distinguish different groups so that e.g., an Okomoyana will be introduced by saying that he's a Trio but an Okomoyana.

13. A macro level classification by Greenberg (1987) places Cariban in the GePano-Carib phylum, branch VI of his Amerind.

14. The classifications by Girard and Kaufmann have not been published and were taken from Gildea 1992.

15. Indeed the few Pianakoto words given in Schomburgk (1845:82ff) show a high degree of lexical similarity to Trio.

16. Wayana does, however, exist outside of the Trio community with two villages in Suriname and some in French Guiana and Brazil. The Wayana in Brazil live together and have been fusing with the Aparai. Wayana and Aparai are both Cariban languages and are closely related. At present there is a high degree of bilingualism between the two communities with indications that Aparai is becoming more dominant. I would like to thank Peter Rivière for drawing my attention to this point.

17. Rivière (1963:174) states that the Okomoyana may be related to the Wama, Tiriyometesem or the Ojaricoulet. According to old Okomoyana informants the Trio waged a fierce war against the Okomoyana after a trading session and all but decimated the entire group. 
18. According to Trio informants Sikiyana is another name for Maipuridjana or Maipurisana "tapir people", a group found in Schomburgk (1845:84) as Tshikianas, where Farabee (1924:194) has Chikenas, a supposedly hostile group. As stated by Rivière (1969:21) it is unlikely that Maipurisana is a Trio xenonym. The Trio for tapir is pai. However, the Akuriyo for tapir is maipuri. There is a regular sound correspondance between the palatal fricative /s/ in Trio and the affricate/ts/ in Akuriyo.

19. The Waiwai is a larger unit also belonging to the East-West Guiana group in Durbin's (1977) linguistic classification and to the Guiana branch in Kaufman's classification. According to Yde (1965:14), Sirewu (Shereo) is a Waiwai group, some of whom left Guyana to join the Hishkaryana, and others of whom had moved to the north. Derbyshire (1985:xiv), on the other hand, states that the Sherew is a Hixkaryana group, some of whom live among the Waiwai. Durbin's (1977) is the only classification which assigns Waiwai and Hixkaryana to separate branches. The acculturation of these to the Trio refers only to those living among the Trio in Suriname and not to those in Guyana or Brazil. The Sirewu community living in Kwamalasamutu has no active speakers but only a few rememberers. The older Tunayana are all active speakers.

20. Sergio Meira (personal communication) has met some Mawayana in Brazil who still speak their own language. Of the Mawayana in Kwamalasamutu few speak Mawayana, more speak Waiwai, and all speak Trio. Rivière (1963:153) states that Mawayena, as well as Taruma, "belong, or at least used to belong to a different linguistic group." It is possible that Schomburgk's Maopityan and Farabee's Mapidian - pityan is the Wapishiana (Arawakan) word for "human being, person" - are the same as the Mawayana, and that they once spoke an Arawakan language.

21. Cf. Koelewijn 1987:59-64 and 1984:79-90. In this text the storyteller identifies the Trio with the Pirëuyana who were the first people and who mixed with the Aramayana, the Aramiso, and the Maraso by drinking each others' blood. This does not mean, however, that the differences between the groups were then set aside or became blurred, rather, descent is still known.

22. The merits as well as the shortcomings of Frikel's work are outlined in Rivière 1963, 1969.

23. People are classified as being either ëire "dangerous" or ëireta "not dangerous," which means that formerly if one met a group of the category ëire, the strategy was to kill before getting killed oneself.

24. It is now generally accepted that the names Wama and Akuriyo refer to the same group.

25. The identity and status of the Tiriyometesen is unclear. The name is clearly a xenonym, a morphological analysis of which gives us: tiriyo-me t-e-se-n "ones as the Trio." $-m e$ is an adjectivalizer with the meaning "having the quality/attribute of" $t$ - $e$ $s e-n$ is a nominalized form of the verb "to be" meaning "ones to be/being." Informants who still know the name say that they were like the Trio although their language was different.

26. Frikel's Prouyana are the same as the pireujana mentioned above.

27. Under good conditions, this village is about two days by boat from Tëpu and four days under less good conditions. It takes about half an hour by airplane from 
Tëpu. Since no permission was asked from the central government to establish the bible camp (cum village) there, it is unlikely that the authorities know anything about it.

28. Obvious advantages of moving away from the larger settlements are that game resources are more plentiful in less densely populated areas, that is, the Trio do not have to travel quite so far in order to hunt. It is unlikely, however, that new villages will be set up very far from an existing one where there is an airstrip since, apart from considerations arising from medical emergencies, the Trio have become dependent in a material way on goods flown in from town.

29. Kwamalasamutu is the only village that has a granman at present.

30. For a discussion of the traditional social relationships within a settlement, expressed by the term imoiti, the reader is referred to Rivière 1969 and his somewhat revised views in Rivière 1984.

31. The Christmas church service I attended in Kwamalasamutu consisted of a half hour's hymn-singing, and an hour and a half talk by the granman of which fifteen minutes were dedicated to explaining the birth of Jesus and an hour and a quarter explaining how the festivities were to be continued. While some people know the Dutch word "Kerstmis," Christmas, most people simply use the term "December," resulting in the rather incongruous statement I heard on December 26 which translates as "come on, you have to dance with us because yesterday was December."

32. More severe forms of punishment include lashes with a rod. The overseer (BOZ) has voiced some dissent as to whether the punishment fits the crime committed, such as for example imprisonment for adultery. The BOZ has little influence on such matters and, under threat himself, can only refer to a higher authority in town.

33. When the head of a nominal possessive is vowel-initial there is zero realization of the 3 rd person possessive prefix $i$-. These two structures are, however, structurally identical.

34. Formerly villages were abandoned after the death of a village leader and often also after the death of a villager. Nowadays it often is the case that the former house of the deceased is burnt to the ground.

35. Having met some Akuriyo I can only insist that this is a dreadful misnomer. The Akuriyo are even more gentle and soft-spoken than the Trio, moreover they seem to have a penchant for hugging researchers.

36. On more than one occasion I had to deal with some quite aggressive monolingual Trio who reproached me for writing down and speaking their language while they wanted to learn the language of the white people. Thus many people see their lack of knowledge of a European language as a grave disadvantage and hence their sole knowledge of Trio also as such a disadvantage. This attitude is widespread and would seem to be a major source of frustration and eventually leading to a dissatisfaction with their own language.

37. "Silence is a form of anger among the Trio, perhaps the strongest," P. Rivière (personal communication).

38. I was unable to find any traces of the tesemmiken, nor were my informants able to understand or place the word. 
39. My informants preferred to use the term taame kato "say taame" for this type of dialogue.

40. That said, some elders do recognize and appreciate the advantages of not having to sit up all night using "strong" talk simply in order to buy something.

41. The plosives $p, t, k$ are voiceless and unaspirated. Intervocalically there may be a slightly voiced allophonic variant of the $p, t, k$, but this seems to be speaker-dependent.

42. The same distinction seems to be present in Brazil as well. I would like to thank Sergio Meira for sharing with me his knowledge of the Trio language as spoken in Brazil. According to Meira, the $/ \mathrm{k} /$ dialect speakers along the Eastern Paru River may have migrated there from Suriname thus the east-west isogloss may not be very old. At any rate synchronically the distinction does exist.

43. There are sometimes longer periods in which there is no teacher available for Tëpu. Since there is no state or church-run school in Palumeu, the eco-tourism company METS have provided a schoolroom and funds to pay a teacher, however, attempts to find a teacher willing to go to the interior have not yet been successful.

44. Apart from the resort in Palumeu, tourists seldom visit the Trio villages, and thus as predicted by Rivière (1981:7), can be ignored as a factor in the dynamics of this society.

45. As pointed out by Rivière (personal communication), the situation among the Trio in Brazil differs in that they have had uninterrupted schooling in Portuguese since the early $1960 \mathrm{~s}$, thus the level of bilingualism is much higher there. The Surinamese Trio who travel back and forth from Brazil seldom advance further in their knowledge of Portuguese than limited phatic communicative acts such as "hello" and "how are you?"

46. Until March 1998 some Trio assistants, trained either by former missionaries or by the teachers themselves, were employed in the schools. These also taught Dutch and spoke a good deal of Trio in the classroom. Since the government take-over of the schools at the beginning of 1998 assistants without a diploma can no longer be employed. Due to the general low standard of education among the Trio, it is unlikely that a native teacher will emerge in the foreseeable future.

47. If one compares the present situation to that described in Rivière's 1981 report, it would seem that both the literacy and numeracy levels have declined dramatically over the last twenty years. It is now not uncommon to find teenagers who do not know how old they are.

48. This seems to represent a marked change in attitude since Koelewijn's collection of Trio oral traditions, a project that met with great enthusiasm. A number of reasons may be put forward, namely that the Trio are not exactly avid readers in any language, that is, they depend on oral transmission. They realize that unless they can defend themselves in the language of the non-Amerindian, they will always be at a disadvantage and must fear being cheated in negotiations with outsiders.

49. The goods sold in Tëpu are sugar, toothpaste, soap, buckets, and containers.

50. It is often unclear whether the exorbitant prices the Trio ask for a given object are based on their desire to get as much money as they can or whether they truly cannot assess its monetary value. 


\section{Cited in De Goeje 1943:340.}

52. A report by Jacobs of a journey in 1718 (published in IJzerman 1911) mentions Indians called "Drijanen," who since they were found in more or less the same area as where Schomburgk later passed, have been identified by IJzerman (1911:650) as the Trio.

53. Crevaux's translation was: "blancs besoin pas, là enfants morts. terre trou. vites pars, cassave manger pas." Huttar (1997:120, note 7) translates this as: "Whites not wanted ... all children dead ... [they have been] put in [this] hole ... quickly leave ... [there is] no cassava to eat." I agree with him that the last part probably means "leave right away, don't stay around to eat."

54. However, De Goeje's explanation for the reticence of the Trio to be seen or have anything to do with Crevaux was one he heard from Majoli, one of the Trio chiefs, namely that the Ndjukas, in an attempt to save their trade market, had spread rumors that the whiteman was bringing with him not only a pernicious disease but also a few malicious Creoles (De Goeje in Franssen-Herdersschee 1905:945).

55. The last word in Crevaux's list, teke, is also from this pidgin. For more details of this pidgin, see below.

56. The common aim of all these expeditions, initiated by the Commissie tot wetenschappelijk onderzoek van Suriname (Committee for Scientific Research in Suriname) was to chart the country geographically and topographically and to acquire some knowledge of its flora and fauna. A concomitant aim was to collect as much ethnographical information as possible on the indigenous peoples.

57. Date given in Rivière 1969:14.

58. In Trio the word "year" is a verb, i.e. the form iranta-to is a nominalized form referring to the yearing process.

59. For some more detailed comments on the impact of evangelization among the Trio, see Rivière 1981.

60. Thoden Van Velzen and Van Wetering (1988:11) state that the Ndjuka began to move to the Tapanahoni shortly after 1760 . By 1790 the migration had been completed. The fact that the Tapanahoni flows into the Marowijne made this location extremely attractive since they could then have contact with other Creoles, with whites in the coastal area, and with various Amerindian groups.

61. For earlier samples of this pidgin, which De Goeje $(1906,1908)$ called the "Ndjuka-Trio-(Wayana) handelstaal," i.e. trading language, see also Huttar \& Velantie 1997.

62. For the purposes of this paper I am leaving out possible older borrowings from other Amerindian languages, such as e.g., Trio: wirapa "bow" which may be of Tupi origin, cf. uirapára "bow" (Parissier 1903:32).

63. The numerals in this list were collected from old men in Tëpu, those above three were unknown to old men in Kwamalasamutu who used tapüime 'many' for all numbers over three.

64. The abbreviations used in the glosses are: adj. "adjectivalizer;" 3poss "third person possessive prefix, i.e. his/her/their;" nom "nominalizer." The adjectivalizer 
- $m e$ carries the connotation of "having the quality of, having a non-inherent or transient quality." Thus, itamume " 6 " is to be understood as "being its leader, having the function or quality of being." Likewise witoto-me "human being-adj," is not a human being but takes on human qualities or human appearance (this is usually said of spirits who take on human appearance and traits), see also below for the concept "to work."

65. Orthographic $\mathrm{r}$ is a flap which in the environment of back and round vowels is realized as an $\mathrm{l} / \mathrm{.}$

66. It is, however, not clear to what extent older traditions are being resurrected or perhaps replaced by new ones. I was able to witness one ceremony involving seven cayman of varying sizes that had been offered by a man to his father-in-law. The cayman, still alive, were tethered to two posts and taunted by two women with sticks in a dancing formation, then one took a machete and the other a gun. They danced around the cayman, poking at them. Then the said father-in-law took over, likewise taunting them, shouting first at a child among the spectators, then repeating his words to the cayman "atitome kureta manan" "why are you bad?" all the while working himself into a frenzy until he began randomly to chop at the cayman, throwing the chopped off pieces of cayman in the air, until they were all dead. The pieces of the creatures were then gathered up by the women, who in single file dancing and singing, took them to the river to be washed. They were subsequently roasted and eaten. The strangest thing about this ceremony is that as Rivière (personal communication) correctly points out, nothing even remotely similar is mentioned anywhere in the ethnographic literature, neither with reference to the Trio nor to any other group in the Guianas. One explanation I received later was that as a punishment for making fun of one's mother-in-law one had to bring her some live cayman.

\section{REFERENCES}

ALGEMEEN BUREAU VOOR DE STATISTIEK, 1996. Vijfde algemene volks- en woningtelling 1980. Supplement. Paramaribo: ABS.

Crevaux, Jules, 1883. Voyages dans l'Amérique du Sud. Paris: Hachette.

CREVAUX, JUles, P. SAGOT \& LUCIEN ADAM, 1882. Grammaires et vocabulaires Roucouyenne, Arrouague, Piapoco et d'autres langues de la région des Guyanes. Paris: Maisonneuve.

DERBYSHIRE, DESMOND C., 1985. Hixkaryana and Linguistic Typology. Texas: Summer Institute of Linguistics.

DURBin, MARShaLl, 1977. A Survey of the Carib Language Family. In Ellen Basso (ed.), Carib-speaking Indians: Culture, Society and Language. Tucson: University of Arizona Press, pp. 23-28.

EDWARDS, JOHN, 1992. Sociopolitical Aspects of Language Maintenance and Loss: Towards a Typology of Minority Language Situations. In Willem Fase, Koen Jaspaert \& Sjaak Kroon (eds.), Maintenance and Loss of Minority Languages. Amsterdam: John Benjamins, pp. 37-54. 
Farabee, William C., 1924. The Central Caribs. Philadelphia: University of Pennsylvania.

FINDLAY, D.G.A., 1971. Trio en Wayana indianen in Suriname. Paramaribo: s.n.

FoCK, NIELS, 1963. Waiwai: Religion and Society of an Amazonian Tribe. Copenhagen: National Museum.

FRANSSEN HERDERSCHEE, A., 1905. Verslag der Tapanahoni-Expeditie. Tijdschrift van het Koninklijk Nederlandsch Aardrijkskundig Genootschap 22:847-991.

FrIKEL, PROTÁSIO, 1957. Zur linguistisch-ethnologischen Gliederung der Indianerstämme von Nord-Pará (Brasilien) und den anliegenden Gebieten. Anthropos 52:50963.

_, 1964. Das Problem der Pianakotó-Tiriyó. Völkerkundliche Abhandlungen des Niedersächsischen Landesmuseum 1:97-104.

GILDEA, SPIKE L.O., 1992. Comparative Cariban Morphosyntax: On the Genesis of Ergativity in Independent Clauses. Ph.D. Dissertation, University of Oregon, Eugene.

GOEJE, C.H. DE, 1906. Bijdrage tot de ethnographie der Surinaamsche Indianen. Leiden: Brill.

-, 1908. Verslag der Toemoekhoemak-Expeditie (Tumuc-Humac-Expeditie). Leiden: Brill.

-, 1924. Guyana and Carib Tribal Names. Proceedings of the twenty-first International Congress of Americanists: Held at The Hague, August 12-16, 1925, pp. 212-16. The Hague: Brill.

_, 1943. Neolithische Indianen in Suriname (met gegevens der Expeditie Ahlbrinck 1938). Leiden: Brill.

GREENBERG, JOSEPH H., 1987. Language in the Americas. Stanford: Stanford University Press.

Huttar, George L. \& Frank Velantie, 1997. Ndyuka-Trio Pidgin. In Sarah G. Thomason (ed.), Contact Languages: A Wider Perspective. Amsterdam: John Benjamins, pp. 99-124.

IJZERMAN, J.W., 1911. Twee reizen van Paramaribo, een naar de Parima in 1718 en een naar de Boven-Corentijn in 1720. Tijdschrift van het Koninklijk Nederlandsch Aardrijkskundig Genootschap 28:648-61.

KÄYSER, C.C., 1912. Verslag der Corentijn-expeditie. Tijdschrift van het Koninklijk Nederlandsch Aardrijkskundig Genootschap 39:442-514.

KOELEWIJN, CEES [KEISI], 1984. Tarëno tamu inponopï panpira. Leusden: Algemeen Diakonaal Bureau. Vols.1\&2.

-, (In collaboration with Peter Rivière.) 1987. Oral Literature of the Trio Indians of Surinam. Dordrecht, Netherlands: Foris.

LOUKOTKA, CESTMIR, 1968. Classification of South American Indian Languages. Los Angeles: Latin American Center, University of California. 
PARISSIER, J.-B., 1903. Essai de lingua geral ou Tupi (Amazonie). Paris: Imprimerie Apostolique.

RIVIÈRE, PETER, 1963. An ethnographic Survey of the Indians on the Divide of the Guianese and Amazonian River Systems. B.Litt. Thesis, University of Oxford.

-, 1966. A Policy for the Trio Indians of Surinam. Nieuwe West-Indische Gids 2\&3:95-120.

-, 1969. Marriage among the Trio: A Principle of Social Organisation. Oxford: Clarendon.

-, 1971. The Political Structure of the Trio Indians as Manifested in a System of Ceremonial Dialogue. In T.O. Beidelman (ed.), The Translation of Culture: Essays to E.E. Evans-Pritchard. London: Tavistock, pp. 293-311.

-, 1981. A Report on the Trio Indians of Surinam. Nieuwe West-Indische Gids $1 \& 2: 1-38$.

—, 1981. "The Wages of Sin is Death": Some Aspects of Evangelisation among the Trio Indians. Journal of the Anthropological Society of Oxford 12(1):1-13.

-, 1984. Individual and Society in Guiana: A Comparative Study of Amerindian Social Organization. Cambridge: Cambridge University Press.

SCHMIDT, LODEWIJK, 1942. Verslag van drie reizen naar de Bovenlandsche Indianen. Paramaribo: Department Landbouwproefstation in Suriname.

SCHOMBURGK, ROBERT H., 1845. Journal of an Expedition from Pirara to the Upper Corentyne and from Thence to Demerara. Journal of the Royal Geographical Society of London 15:1-104.

Thoden VAN Velzen, H.U.E. \& W. VAN WeTERING, 1988. The Great Father and the Danger: Religious Cults, Material Forces, and Collective Fantasies in the World of the Surinamese Maroons. Dordrecht, Netherlands: Foris.

VERNOOIJ, JOOP, 1989. Indianen en kerken in Suriname: Identiteit en autonomie in het binnenland. Paramaribo: Stichting Wetenschappelijke Informatie.

Whitehead, Neil L., 1988. Lords of the Tiger Spirit: A History of the Caribs in Colonial Venezuela and Guyana, 1498-1820. Dordrecht, Netherlands: Foris.

YDE, JENS, 1965. Material Culture of the Waiwai. Copenhagen: National Museum of Copenhagen.

EITHNE B. CARLIN

KITLV/Royal Institute of Linguistics and Anthropology

Leiden, The Netherlands 